\title{
Validation of relevance of optional attributes and place attachment and duration of exercise
}

\author{
Kim Jae-Deung and Yoo Jung-In \\ University of Suwon, Korea University, Korea \\ jady0417@suwon.ac.kr,surfyji@korea.ac.kr
}

\begin{abstract}
This study influenced gender and exercise sustainability as an optional attribute of water sports participants. Click on the icon in the rankings to win a swarm. First, reliability analysis and confirmatory factor analysis were performed using SPSS WIN 21.0 and AMOS 21.0 statistical programs. Second, an analysis was conducted to verify the difference of measurement variables based on demographic characteristics. Third, the parameters are combined to perform integral analysis. Verifying the last influence. First, there was a statistically significant difference between the variables according to demographic characteristics. Second, there is a statistically or negatively related relationship between the measured variables. Finally, the selected attributes have a statistically significant effect on place attachment and duration of exercise. In conclusion, the optional attributes of water sports participants have a positive effect on place attachment and duration of exercise.
\end{abstract}

Keywords: Continuous exercise, Optional attributes, Place attachment, Regression analysis, Water sports

\section{Introduction}

As sports participants increase their interest in health and well-being and increase their demand for and participation in nature-friendly sports activities, water sports are becoming important among various sports[1]. Water sports are nature-friendly sports that participants not only harmonize with nature, but also provide challenges, adventure pursuits, and fun[2] The motivation and choice attributes of water sports participants suggest that they are closely related to their various needs. In general, the selection attribute is explained by the consumer's choice of product or brand using information gathered through information search [3]. In addition, this selective attribute not only provides important clues in determining consumers' behaviors, but also has a close relationship with practice in practice[4][5].

Place attribution is explained by emotional and emotional, not only the sense of belonging to a specific place, but also the expression of functional, emotional, and behavioral meanings[6]. This place attribution is not only an emotional solidarity that appears to individuals, but also reveals that complex and independent dimensions are integrated[7]. In this study, we found that self-efficacy and self-efficacy were significantly related to selfefficacy and self-efficacy[8]. In addition, it is important to note that this is not the case in this

Article history:

Received (April 4, 2019), Review Result (June 19, 2019), Accepted (September 2, 2019) 
study. The results of this study are as follows. First, the results of this study are as follows. In addition, exercise participation, exercise intensity, and exercise time are closely related to exercise persistence[9]. Therefore, the purpose of this study is to investigate the relationship between the optional attributes of water sports participants and the place of attachment and the duration of exercise.

In addition, it is important to note that this is not the case in this study[10]. Looking at previous studies associated with exercise adherence reveals dalrajindago depending on personal characteristics and the environment, the participants of the attitudes and beliefs, and psychological factors such as satisfaction[11]. In addition, exercise participation, exercise intensity, and exercise time are closely related to exercise persistence[9]. Therefore, the purpose of this study is to investigate the relationship between the optional attributes of water sports participants and the place of attachment and the duration of exercise.

\section{Research method}

\subsection{Subjects}

The subjects of this study were 200 people who participated in water sports on regular basis in the water sports field in Seoul.

Table 1. Demographic characteristics

\begin{tabular}{|c|c|c|c|}
\hline & & frequency & $\%$ \\
\hline \multirow{2}{*}{ gender } & $\operatorname{man}$ & 92 & 51.1 \\
\hline & woman & 88 & 48.9 \\
\hline \multirow{4}{*}{ Athletic experience } & 2 years Less than & 54 & 30.0 \\
\hline & 2 3 years Below & 44 & 24.4 \\
\hline & 4 5 years Below & 22 & 12.2 \\
\hline & 6 years more than & 60 & 33.3 \\
\hline \multirow{4}{*}{ Age } & 20 's & 20 & 11.1 \\
\hline & 30 's & 64 & 35.6 \\
\hline & 40 's & 87 & 48.3 \\
\hline & 50's more than & 9 & 5.0 \\
\hline \multirow{3}{*}{ Participation } & Once a week & 21 & 11.7 \\
\hline & 2-3 a week & 110 & 61.1 \\
\hline & 4-5 a weeks & 49 & 27.2 \\
\hline \multicolumn{2}{|c|}{ total } & 180 & 100.0 \\
\hline
\end{tabular}

\subsection{Measuring tools}

In order to measure the optional attributes of the water sports participants, the scale of the optional attributes was measured by [12] based on the questionnaire developed by Carmichael[13]. The results of this study are as follows. Second, the measurement items related to place attachment were composed of 10 items with 6 items that measure place 
dependency and 4 items that measure place identity. Finally, continuity of exercise was used to measure the Exercise Adherence Questionnaire (EAQ) of[14], which was developed according to the Korean situation[15].

\subsection{Research procedure}

In order to answer the questionnaire effectively, the researcher explained the purpose and purpose of the study to the participants of the water sports, and distributed the questionnaire to the subjects who participated in the study and participated in the study. We tried to secure the reliability of the data by explaining the questionnaire to the understanding of the questionnaires when they were not understood. However, despite these efforts, it was immediately excluded from the questionnaire response if it was judged to be lack of understanding, and the retrieved questionnaire was screened immediately such as omission of questions and uniform response to a single score. Secondly, of the respondents.

\subsection{Data analysis}

The data used in this study consisted of confirmatory factor analysis of reliability analysis of applied scales, multivariate analysis to verify differences according to demographic characteristics, correlation analysis and regression analysis to examine the relationship between measurement variables.

\section{Research results}

\subsection{Differences in selection attributes, place attachment, and exercise duration according to gender}

There was a significant difference between the two groups(Willks' Lambda $=.783, \mathrm{~F}=$ $5.249, \mathrm{p}<.000)$. As for the difference, the female participants were higher in all the sub factors of the optional attributes than the male participants, and the place dependency was higher in male and the female in place identity. Finally, in the tendency and intensiveness of the exercise, the female was higher and the male was higher than likelihood.

\subsection{Selection attributes, place attachment, and continuous exercise according to exercise experience}

The difference between the two groups was significant Choice attribute, place attachment, and exercise persistence level were high(Willks' Lambda $=.631, \mathrm{~F}=3.104, \mathrm{p}<.000$ ). Especially, in the optional attribute, all the sub factors were higher than 2 years. The place dependence of place attachment was higher than 6 years, and place identity was less than 2 years. Finally, tendency during exercise was higher than that of 6 years or more, and less than 2 years or more than 4 to 5 years.

\subsection{Selection attributes according to the number of participation, place attachment, verification of difference in continuous exercise}

There was a significant difference between the two groups (Willks' Lambda $=.804, \mathrm{~F}=$ $2.168, \mathrm{p}<.01)$. As a result of these differences, the program sub - factors of the selected attributes showed a high level of $4 \sim 5$ times a week. In addition, the cost, staff and convenience facilities showed once a week. The place dependence of place attachment was 
high $4 \sim 5$ times per week, and place identity was 1 time per week. The tendency during exercise was high $2 \sim 3$ times in middle, $4 \sim 5$ times in week, and $4 \sim 5$ times in week.

\subsection{Correlation analysis between measurement variables}

Correlation analysis was performed to investigate the relationship between variables set in this study. The analysis showed that the program and the cost of the selected attribute had no significant relationship with the duration of the exercise. The convenience facilities of the selected attribute showed no significant difference between the tendency of the place attachment and the continuation of the exercise, Negative correlation appeared in the possibility of continuing exercise. In addition, there was a statistically significant correlation between variables.

Table 2. Correlation between choice attribute, place attachment, and duration of exercise

\begin{tabular}{|c|c|c|c|c|c|c|c|c|c|}
\hline & 1 & 2 & 3 & 4 & 5 & 6 & 7 & 8 & 9 \\
\hline Program & 1 & & & & & & & & \\
\hline Expense & $.551^{* *}$ & 1 & & & & & & & \\
\hline Staff & $.302^{* *}$ & $.437^{* *}$ & 1 & & & & & & \\
\hline Facilities & $.299^{* *}$ & $.431^{* *}$ & .121 & 1 & & & & & \\
\hline Dependence & $.328^{* *}$ & $.264^{* *}$ & $.364^{* *}$ & -.021 & 1 & & & & \\
\hline Identity & $.348^{* *}$ & $.330^{* *}$ & $.324^{* *}$ & .176 & $.650^{* *}$ & 1 & & & \\
\hline Tendency & $.186^{*}$ & .069 & $.181^{*}$ & -.157 & $.552^{* *}$ & $.589^{* *}$ & 1 & & \\
\hline Possibility & .004 & -.009 & $.353^{* *}$ & $-.185^{*}$ & $.264^{* *}$ & $.414^{* *}$ & $.573^{* *}$ & 1 & \\
\hline Reinforcement & $.253^{* *}$ & .161 & $.343^{* *}$ & .000 & $.375^{* *}$ & $.755^{* *}$ & $.640^{* *}$ & $.678^{* *}$ & 1 \\
\hline
\end{tabular}

\subsection{How selected attributes affect place attachment}

The results of the multiple regression analysis were as follows: First, the influence of the optional attributes on the place dependence of place attachment was found to be as follows: program $(\beta=.252)$, cost $(\beta=.075)$ The sub-factors showed a positive effect on the place dependency. The explanation variable of the final regression model was $20.6 \%$ and the $\mathrm{F}$ value was 7.326, which was statistically significant at the significance level $p<.001$ Respectively. Second, the effects of the optional attributes on the place identity of the place attachment were found to have a positive effect on the place identity of the program $(\beta=.216)$ and the employees $(\beta=.209)$, The explanatory variable was $18.4 \%$, and the $F$ value was 6.358 , which was statistically significant at the significance level $\mathrm{p}<.001$.

\subsection{The effect of place attachment on the duration of exercise}

The results of the multiple regression analysis were as follows: First, the dependence ( $\beta$ $=.293)$ and identity $(\beta=.399)$ All the sub-factors had a positive effect, and the explanation variable of the final regression model was $39.6 \%$ and the $F$ value was 97.755 , which was statistically significant at the significance level $\mathrm{p}<.001$. Second, the effect of place attachment 
on the likelihood of continuing exercise was positively affected only by the sub-factor of place identity $(\beta=.420)$, and the explanation variable of the final regression model was $17.2 \%$ Was 11.921 and significance level $\mathrm{p}<.001$ was statistically significant. Third, place dependence $(\beta=-2.559)$ has a negative effect on place intention, whereas place identity ( $\beta$ $=.885$ ) only affects positively Respectively. The explanatory variable of the final regression model was $59.4 \%$, and the $\mathrm{F}$ value was 84.026 , which was statistically significant at the significance level $\mathrm{p}<.001$.

\subsection{Effects of optional attributes on exercise duration}

The results of the multiple regression analysis were as follows: First, the influence of the optional attributes on the tendency of the exercise duration was examined by the program ( $\beta$ $=.220)$ and convenience facilities $(\beta=.399)$, The explanatory variable of the final regression model was $10.4 \%$, and the $\mathrm{F}$ value was 3.274 , which was statistically significant at the significance level $\mathrm{p}<.05$. Second, the effect of selection attributes on the likelihood of continuing exercise was positively affected by employees $(\beta=.426)$, and the explanatory variance of the final regression model was $18.6 \% 6.449$ with significance level $\mathrm{p}<.001$. Finally, the effects of the optional attributes on the reinforcement during exercise were positively affected by the program $(\beta=2.057)$ and the employees $(\beta=-3.242)$. The explanatory variable of the final regression model was $15.2 \%$, and the $\mathrm{F}$ value was 5.074 , which was statistically significant at the significance level $\mathrm{p}<.01$.

\section{Conclusion}

Selective attributes of water sports participants, which are nature-friendly sports activities for health and well-being, have a positive impact on the sense of belonging and the duration of exercise.

\section{Acknowledgements}

This work was supported by the University of Suwon, 2018.

\section{References}

[1] Lee, K. M., and Kim, J. Korean Journal of Physical Education, vol.46, (2007)

[2] Kim, D. J., and Yang, M. H., The Korean Society for the Study of Physical Education, vol.8, (2004)

[3] Yoon, J. H., Journal of Tourism and Leisure Research, vol.22, no.5, (2010)

[4] Kim, H. H., and Park, I. H., The Korean Journal of Physical Education, vol.57, (2018)

[5] Cronin, J, J., and Taylor, S. A., Journal of Business Research, vol.24, (1992)

[6] Bricker, K. S., and D. L. Ketstetter, Leisure Sciences, vol.22, (2000)

[7] Lee, J. S., Lee, B. S., Choi, J. H. and Han, Y. S., Korean Journal of Child Studies, vol.30, (2009)

[8] Lee, D-H., Journal of Sport and Leisure Studies, vol.71, (2018)

[9] Choi, M. S., and Kim, S. M., The Korean Journal of Physical Education, vol.55, (2016)

[10] Corbin, C. D., Welk, G. J., Lindsey, R., and Corbin,W R., Concepts of physical fitness, New York: McGrawHill companies, (2003)

[11] Chun, T. J., The Korean Journal of Physical Education, vol.44, (2005)

[12] Kim, D. E., The Graduate School of Sport and Leisure Studies, Yonsel University, (2003)

[13] Carmichael B., Journal of Marketing Research, vol.14, (1997)

[14] Corbin, C. B., and Lindsey R., Concepts of physical fitness, Dubuque, IA: Wm. C. Brown Communications, (1994) 
[15] Oh, S. H., Song, Y. K., Kim, H. J., Her, M. H.,\& Cho, J. H. The Korean Journal of Measurement and Evaluation in Physical Education and Sport Science. 2.(2000)

\section{Authors}

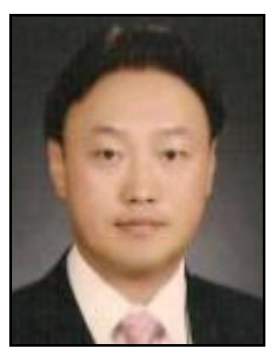

\section{Kim, Jae-Deung}

Dept. Sports Science, University of Suwon. Professor

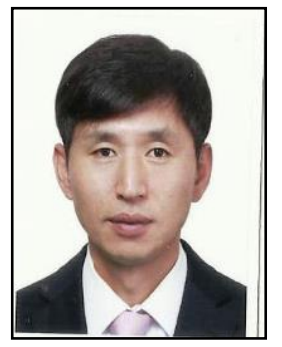

\section{Yoo, Jung-In}

Dept. Physical Education, Korea University. Research professor. 